\title{
1-D SIMULATION MODEL OF A PROGRESSIVE FLOW CONTROLLER FOR HYDROSTATIC BEARINGS
}

\author{
Edler, J.*; Tic, V. ** \& Lovrec, D.** \\ * Graz University of Technology, Kopernikusgasse 24, A-8010 Graz, Austria \\ ** University of Maribor, Faculty of Mechanical Engineering, Smetanova 17, 2000 Maribor, Slovenia \\ E-Mail: joerg.edler@tugraz.at, vito.tic@um.si,darko.lovrec@um.si
}

\begin{abstract}
Hydrostatic bearings in machine tools are used for qualitative highest demands. On the one hand, they are used in precision machines, for example, in grinding machines, to get high precision and the highest quality in the production. On the other hand, they are used in machines with high forces during the production process. Generally hydrostatic bearings are characterised by a good damping behaviour and good stiffness of the bearing, as well as wear resistance and nearly no friction in the bearing (fluid friction), thus, no loss of accuracy over the entire lifetime of the machine tool. A progressive flow control is needed in the bearing to get a nearly constant gap in the hydrostatic bearing, which is independent of the load on the bearing. In our case the progressive flow control works with a piston in combination with a control edge and a mechanical spring. The shape of the control edge is essential to get a nearly constant gap in the hydrostatic bearing. Therefore, a 1-D simulation model of the progressive flow control was developed and implemented in an existing 1-D simulation model of hydrostatic bearings to predict the behaviour of the hydrostatic bearing, for example, in machine tools. (Received in December 2018, accepted in May 2019. This paper was with the authors 1 month for 1 revision.)
\end{abstract}

Key Words: Hydraulic, Hydrostatic Bearing, Flow Control, Simulation

\section{INTRODUCTION}

\subsection{General}

Hydrostatic bearings are used widely in technical applications. For instance, as bearings in axial and radial piston machines, or as bearings of ship propellers $[1,2]$. In the machine tool industry, hydrostatic bearings are used, especially in precision machines (e.g. grinding machines), or in machines with high cutting forces (e.g. the heavy cutting process). For both mentioned and other similar applications within the field of hydraulic components [3], the biggest advantage and the reason why this expensive kind of bearing is installed in machine tools is the good damping behaviour and the wear-free operation of the hydrostatic bearing.

Chen et al. [4], for instance, investigated the dynamic and static characteristics of hydrostatic bearings, especially of spindles for machine tools. They developed a mechanical model of a hydrostatic bearing. In this model, the fluid is also considered, but not the whole system of pre-throttling in combination with the hydrostatic bearing. Edler and Steffan [5] made the same investigations, but not on the hydrostatic bearings of spindles; they investigated the hydrostatic bearings of the linear axis of a grinding machine. Liang et al. [6] also developed a method to calculate the static performance of hydrostatic bearings, but they also didn't consider the pre-throttling of the fluid supply of the bearing.

For precision machining, for instance grinding machines, the whole system fluid supply must be considered. Therefore, investigations must be done to get an exact load spectrum for the simulation. Investigations from Steffan et al. [7] showed, for example, the cutting forces during a noncircular grinding process. These forces are the load on the hydrostatic bearing and the behaviour of the bearing, which results directly in the precision of the workpiece, and in the surface quality of the workpiece. Slow changes of the load have a direct correlation with the gap in the hydrostatic bearing, and, therefore, a direct correlation to the precision of 
the workpiece. The damping behaviour of the bearing is important when the load is changing with a high frequency and has a direct correlation to the quality of the surface of the workpiece. The good damping characteristics of hydrostatic bearings are the result of the geometry of the bearing, and the fact that a fluid with a much lower stiffness than the stiffness of steel, is in the gap of the bearing. It can be said that the damping behaviour of a hydrostatic bearing (and similar components) results from the geometry of the bearing and the used fluid $[8,9]$. The resulting gap in the hydrostatic bearing depends on the load on the bearing, the used fluid, and which kind of pre-throttling is used. The same investigations of the vibration transmission of hydrostatic bearings of a precision machine were done by Kim et al. [10].

3-D investigations of hydrostatic bearings were done by Horvat and Braun [11]. They used FEM 3-D methods to determine the flow and pressor fields in hydrostatic bearings, but this method is very time intensive to determine the time behaviour of a hydrostatic bearing of a machine tool; for this case 1-D methods are more effective.

\subsection{Hydrostatic bearings}

Fig. 1 shows the general construction of a hydrostatic bearing. It consists of a pocket (1) with the fluid supply of the bearing. The gap of the bearing (2) and the part which should be pressed (3).
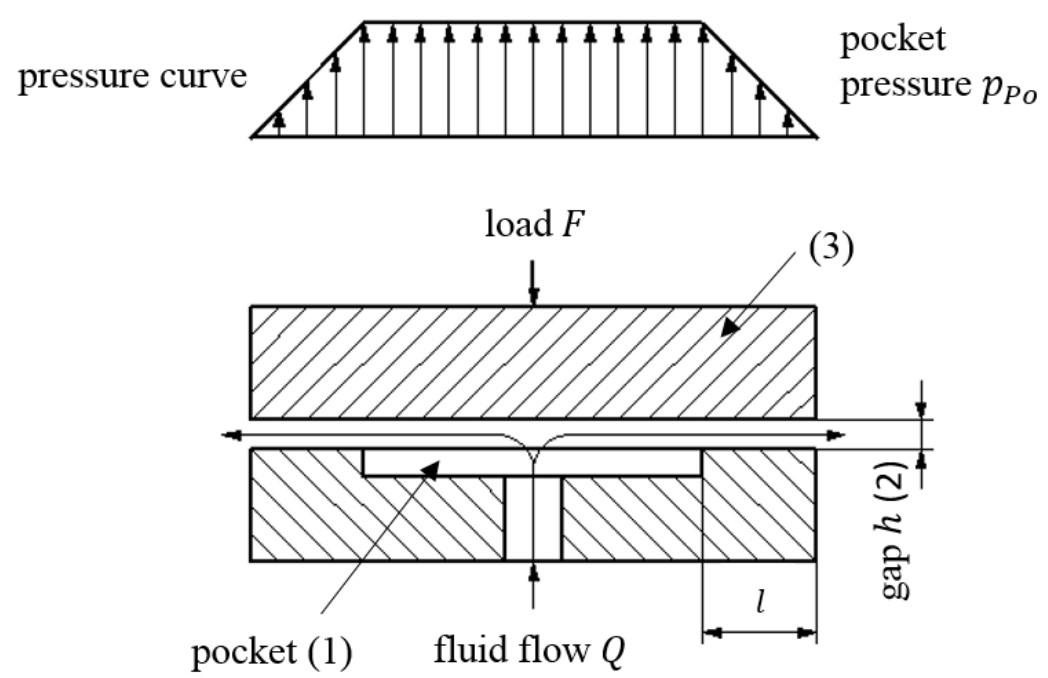

Figure 1: Construction and pressure curve of a hydrostatic bearing.

Pre-throttling of the fluid supply is needed for the bearing to work correctly. Therefore, normally constant throttles are used (e.g. orifices, throttles or a capillary). It can be said, that the system of a hydrostatic bearing includes a constant pre-throttle and the hydrostatic bearing itself, which can be seen as a variable throttle. When the load is changing on the bearing, the gap of the bearing is also changing, because there is no control mechanism to get a constant gap, see Fig. 2.

The flow through the bearing must be controlled to get a nearly constant gap which is independent of the load. Therefore, more possibilities exist. The first possibility is to measure the height of the gap and to control the flow in a closed loop control with a servo valve. For an application in a production machine this solution is not the best one, because a lot of hydrostatic bearings are installed in production machines and the solution is too expensive. 


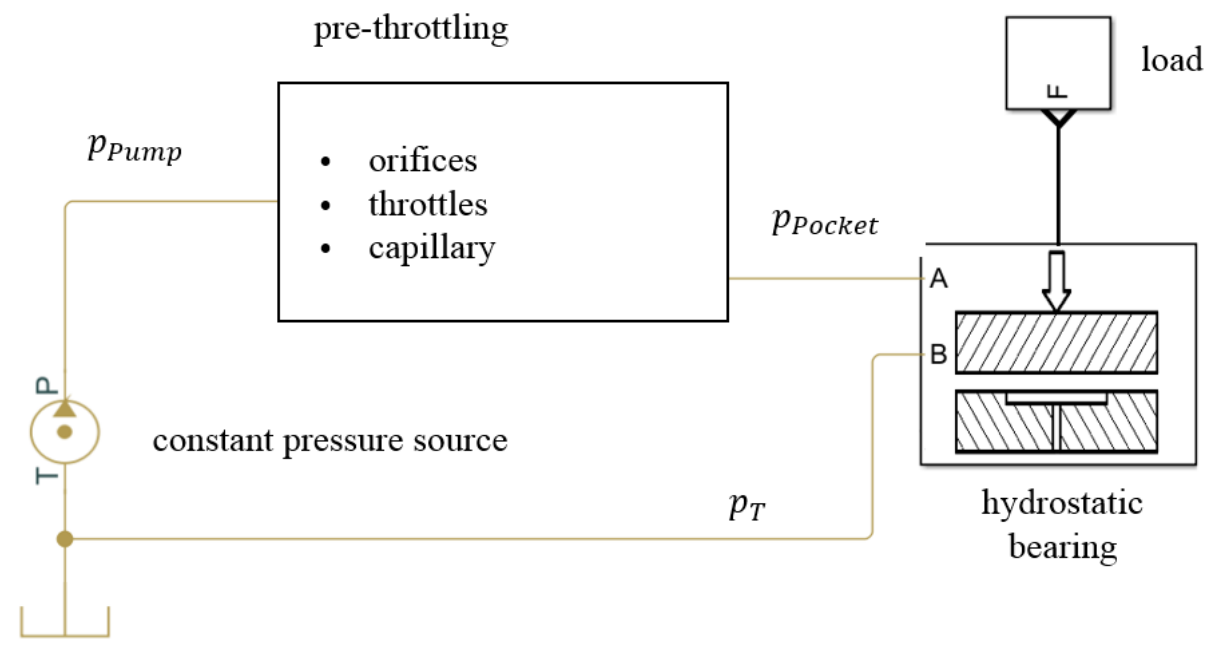

Figure 2: System of hydrostatic bearing.

The other kind to control the gap of a hydrostatic bearing is to use a valve as pre-throttle which is a progressive flow controller. Eq. (5) describes the flow through a rectangular gap which is used in a rectangular hydrostatic bearing. Approximately an average length $b$ was used in the calculation. The pressure in the pocket results from the load on the hydrostatic bearing. It can also be seen that the gap of the bearing changes with the third potency. The double load results in a gap which is 8 times smaller. To get a nearly constant gap in the hydrostatic bearing only the flow could be controlled. Therefore, a progressive flow controller is used. Schönfeld [12] developed a progressive flow control valve which works with a membrane to control the flow. In this work, a progressive flow controller is used which works with a piston and a spring. The piston has a special shape to generate a control edge in combination with the housing of the piston, and the shape of the control edge must be calculated separately for each variation of hydrostatic bearing.

\section{PROGRESSIVE FLOW CONTROLLER}

\subsection{Description of the controller}

Fig. 3 shows the correlation between the flow and the hydrostatic pressure in a hydrostatic bearing with a constant gap in the bearing. The progressive flow controller must now have the same pressure-flow behaviour as the hydrostatic bearing.

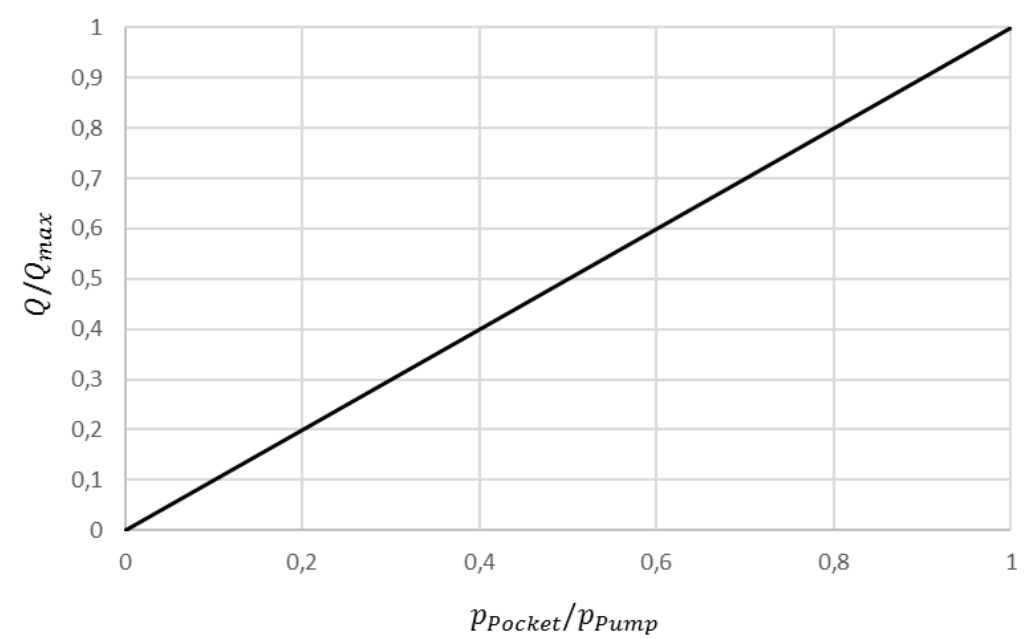

Figure 3: Correlation between the flow and the hydrostatic pressure in a hydrostatic bearing provided with a constant gap height. 
Therefore, a simple piston controller is used, which controls the flow through the hydrostatic bearing independent of the pressure in the pocket of the bearing by a control edge on the piston, see Fig. 4. Piston (1), with different areas, works together with the spring (2). To get no oscillation of this mass-spring combination a damping volume (3) is installed in the controller. The force balance between the hydrostatic forces on the different areas of the piston and the force of the spring determine the position of the piston in the controller and, thereby, the position of the variable throttle.

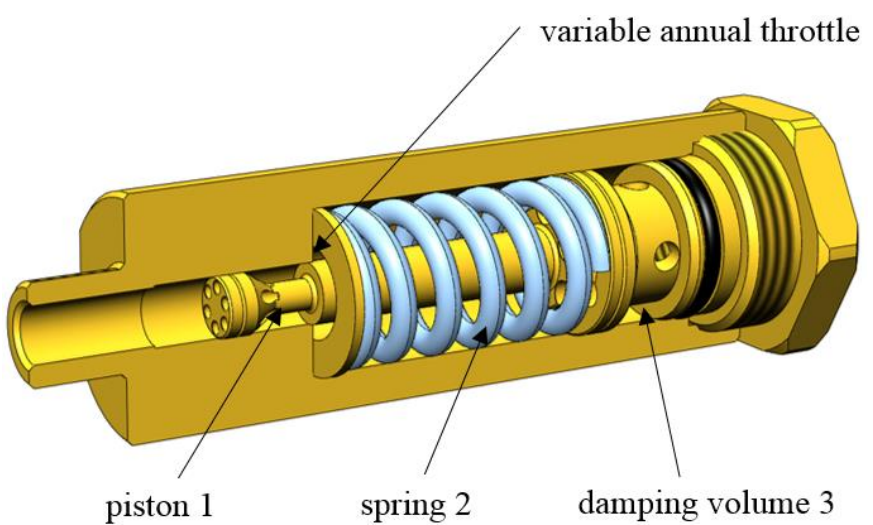

Figure 4: Cross-section of the progressive flow controller.

The variable throttle in the controller is built up as an annular throttle. This annular throttle has no constant gap, and the shape of these throttle represents the pressure-flow behaviour of the hydrostatic bearing. A first calculation of these shapes is presented by Mörwald et al. [13]. In these calculations only static conditions in the controller are considered. In this paper, the inertia effects in the controller and pressure raising effects in the hydrostatic bearing are also considered. With this extension, the shape of the annular orifice can be calculated more accurately.

\subsection{Mathematical model of the progressive flow controller}

The progressive flow controller is built up of two parts in physical terms. The first one is the mechanical part, which includes the mass of the control-piston, the spring and the damping element, and is described in Eq. (1).

$$
m_{K} \ddot{x}+F_{R}(\dot{x})=-K_{F} x-4 \frac{8 \eta l_{D}}{\pi r_{D}^{4}} A_{D} \dot{x}+\Delta p_{F C}(x) A_{F C}
$$

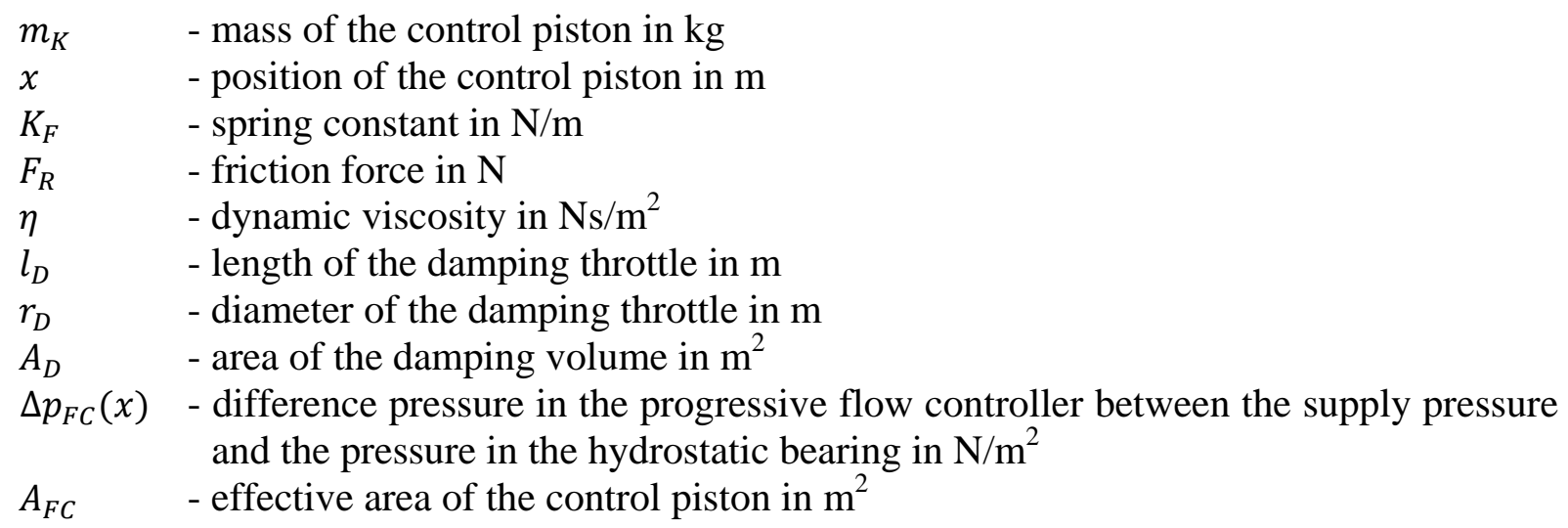

The second part is the fluid part, which calculates the flow through the annular throttle. This equation applies if there is no flow at right angles to the main flow direction. Since, in 
the predominant case, the flow is very small in relation to the main flow direction, it can be neglected. Thus, the Hagen Poisson's law can be applied, see Eq. (2).

$$
Q_{F C}(x)=\frac{\pi d_{m, F C} h(x)^{3} \Delta p_{F C}(x)}{12 \eta x}
$$

$Q_{F C}(x)$ - flow through the progressive flow controller in $\mathrm{m}^{3} / \mathrm{s}$

$d_{m, F C} \quad$ - middle diameter of the annular gap of the progressive flow controller in $\mathrm{m}$ $h(x) \quad$ - gap height in $\mathrm{m}$

To calculate the shape of the control edge of the annular throttle Eq. (2) must be transformed into a differential form, see Eq. (3). This equation is a nonlinear first order Differential Equation, and will be solved numerically in a separate block in the simulation.

$$
\frac{\mathrm{d} Q_{F C}}{\mathrm{~d} x}=\frac{\pi d_{m, F C} h(x)^{2}\left(3 x \Delta p_{F C}(x) h^{\prime}(x)+h(x)\left(x \Delta p_{F C}^{\prime}(x)-\Delta p_{F C}(x)\right)\right)}{12 \eta x^{2}}
$$

The flow into the damping part is considered in the mechanical equation.

\subsection{Mathematical model of the hydrostatic bearing}

The hydrostatic bearing will also be described by the force balance on the bearing, see Eq. (4), as the mechanical part.

$$
m_{B} \ddot{y_{B}}=F_{L}-\Delta p_{B}\left(F_{L}\right) A_{B}
$$

$m_{B} \quad$ - mass on the bearing in $\mathrm{kg}$

$y_{B} \quad$ - gap height of the hydrostatic bearing in $\mathrm{m}$

$F_{L} \quad-$ load on the bearing (including weight force and external forces) in $\mathrm{N}$

$\Delta p_{B}\left(F_{L}\right)$ - difference pressure in the bearing between the pressure in the bearing and the environment pressure in $\mathrm{N} / \mathrm{m}^{2}$

$A_{B} \quad$ - effective area of the hydrostatic bearing in $\mathrm{m}^{2}$

The fluid part of the description is the Hagan-Poisson equation of the flow through a rectangular gap, because a rectangular bearing is installed in the test rig to compare the measurements with the simulation, see Eq. (5). For the hydraulic capacity of the fluid in the bearing and in the pipe between the hydrostatic bearing and the progressive flow controller, see Eq. (6).

$$
Q_{B}\left(F_{L}\right)=\frac{b y_{B}{ }^{3} \Delta p_{B}\left(F_{L}\right)}{12 \eta l}
$$

$Q_{B}\left(F_{L}\right) \quad$ - flow through the hydrostatic bearing in $\mathrm{m}^{3} / \mathrm{s}$

$b \quad$ - width of the rectangle gap of the hydrostatic bearing in $\mathrm{m}$

$y_{B} \quad-$ gap height of the hydrostatic bearing in $\mathrm{m}$

$l \quad-$ length of the rectangular gap of the hydrostatic bearing in $\mathrm{m}$

$$
Q_{K}=\frac{V_{0}}{E_{F l}} \dot{p_{B}}
$$

$Q_{K} \quad$ - flow due to oil compressibility in $\mathrm{m}^{3} / \mathrm{s}$

$V_{0} \quad$ - oil volume in the bearing and the pipe in $\mathrm{m}^{3}$

$E_{F l} \quad$ - compression Module of the oil in $\mathrm{N} / \mathrm{m}^{2}$

\subsection{Complete system}

To calculate the shape of the control edge of the progressive flow controller the hydraulic capacity can be neglected, because only static conditions are considered. In this case, the flow through the hydrostatic bearing and the flow through the progressive flow controller must be 
the same, provided that the gap height of the hydrostatic bearing is constant. The pressure in the hydrostatic bearing depends on the load of the bearing. The position of the control piston with the control edge of the progressive flow controller, depends on the pressure in the hydrostatic bearing. It can be said that there is a direct dependency between the load on the bearing and the position of the piston of the progressive flow controller, see Eq. (7) and the shape can be calculated of the control edge of the progressive flow controller.

$$
Q_{B}\left(F_{L}\right)=Q_{F C}(x)
$$

Eq. (3), to calculate the shape of the control edge of the progressive flow controller, is in a differential form, so it is also necessary to transform the equation of the hydrostatic bearing into a differential form. When we look at Fig. 4 it can be seen that the differential form of the equation of the flow through the hydrostatic bearing is a constant value under the proviso that the gap height of the hydrostatic bearing is constant, see Eq. (8), which is the reciprocal value of the hydraulic resistance $R_{H}$ of the hydrostatic bearing.

$$
\frac{\mathrm{d} Q_{B}\left(F_{L}\right)}{\mathrm{d} \Delta p_{B}}=\frac{b y_{B}{ }^{3}}{12 \eta l}=\text { const }
$$

To validate the calculated shape of the control edge of the progressive flow controller the simulation will be verified with measurements on a test rig [5]. These measurements are, in one case, static, and in the other case, dynamic measurements. To get better results for the dynamic cases, the hydraulic capacity, Eq. (6), is considered in the simulation.

\subsection{Numerical implementation}

As described in Section 2.4, there is a direct dependency between the load $F$ on the hydrostatic bearing and the position $x$ of the control piston of the progressive flow controller. That means that, in the numerical calculation for each load step, the load $F$ will be increased and the shape $r(x)$ ( $r$ is the radius of the control piston in the progressive flow controller) will be calculated of the control edge of the progressive flow controller. One point must be considered in that calculation, that the shape of all the load steps is fixed first. Each load step $\Delta F$ is a way $\Delta x$ of the control piston in the progressive flow controller. In Fig. 5 it can be seen that only the shape of the control edge for the small value of $\Delta x$ will be calculated, and the rest of the shape is fixed. Nevertheless, it is necessary to use Eq. (3) to calculate the flow through the progressive flow controller.

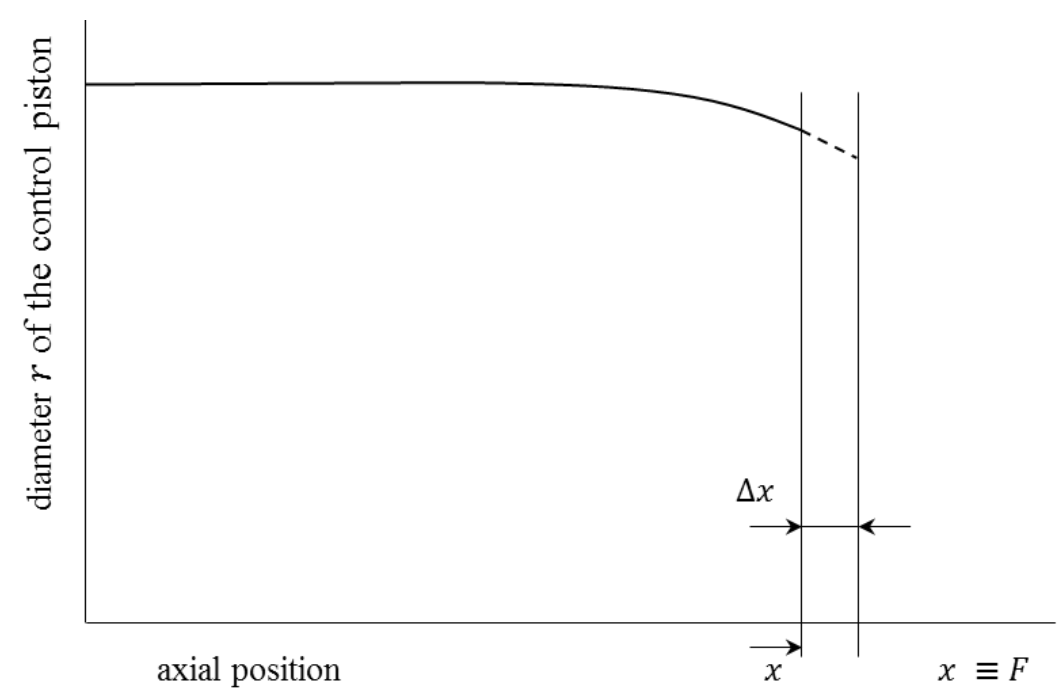

Figure 5: Calculation of increment $\Delta x$ on the control piston to calculate the shape of the control edge on the control piston. 
Fig. 6 shows the flow chart of the calculation of the control edge of the progressive flow controller. This calculation is done as a static calculation and, therefore, the dynamic parts in the equation of the force balance, Eq. (1) and Eq. (4), can be neglected. The loop in the calculation is necessary, because the shape of the control edge of the progressive flow controller is calculated iteratively. In this case, is it not necessary to solve a system of Differential Equations, only the flow through the control edge must be integrated.

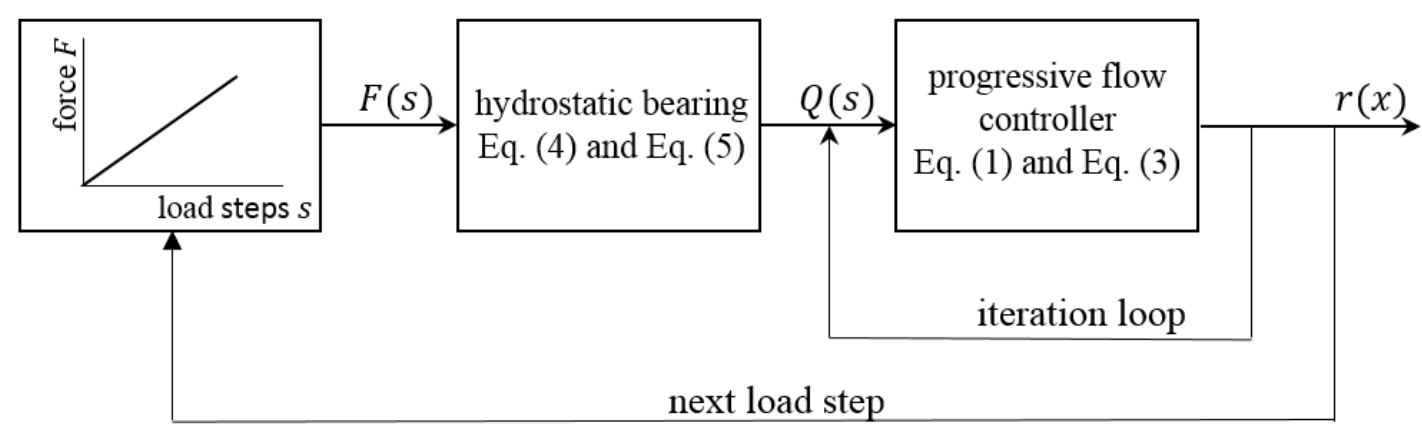

Figure 6: Flow chart of the numerical calculation of the shape of the control piston

For the validation, the flow chart is a little bit different, see Fig. 7. In this case, the shape of the control edge is given and the gap height $h(t)$ of the hydrostatic bearing will be calculated. Here, the dynamic terms of Eqs. (1) and (4) are considered. A system of Differential Equations must be solved, which includes Eqs. (1), (3), (4), (5) and (6). In this case, is it also necessary to use Eq. (3) instead of Eq. (2), because the gap height is not constant, and so the flow through the gap must be integrated. The boundary conditions are the given supply pressure $p_{p}$, the load on the bearing $F(t)$ and the shape of the control edge $r(x)$ (which is a result from the previous calculation).

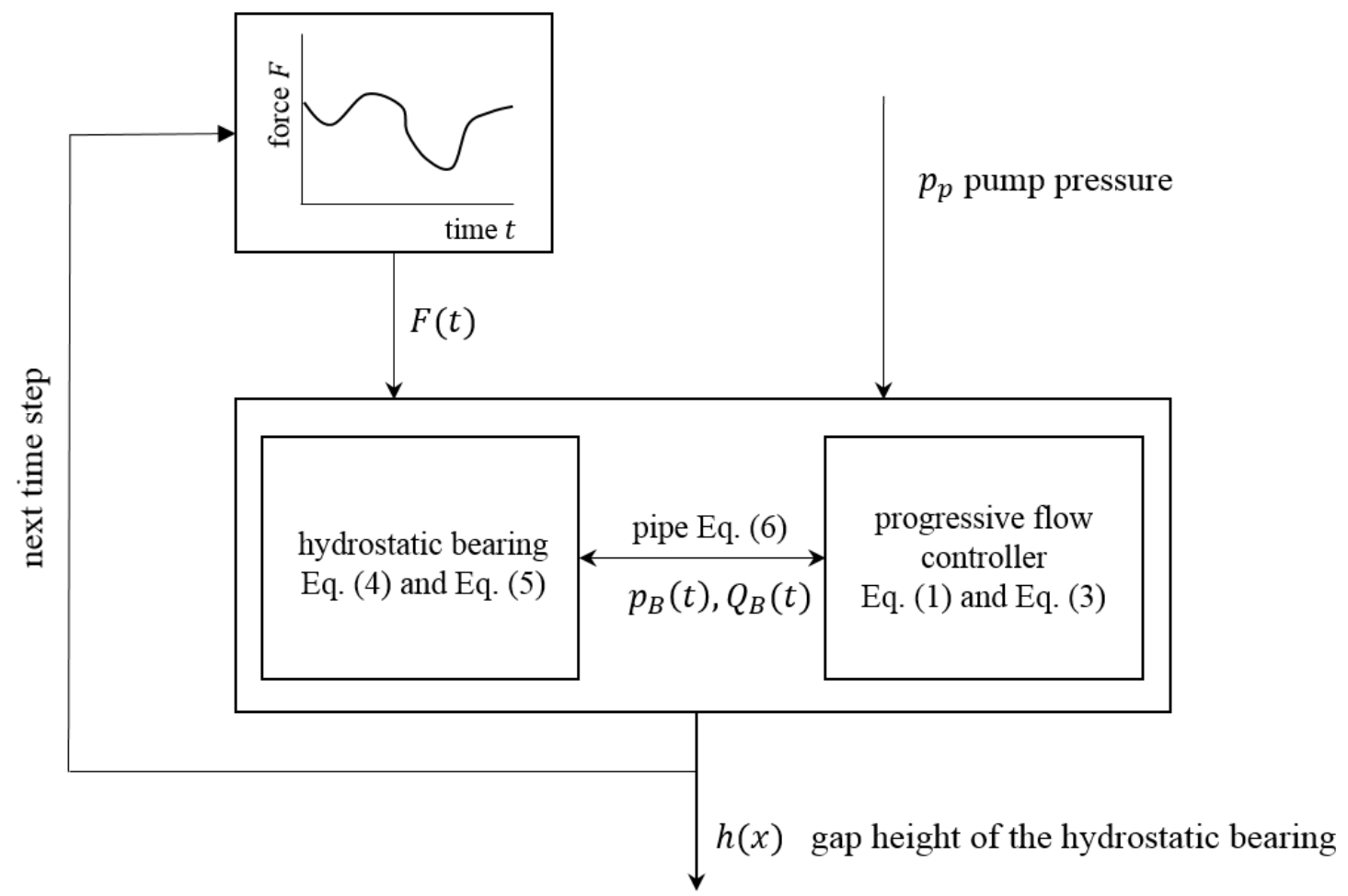

Figure 7: Flow chart of the numerical calculation of system progressive flow controller and hydrostatic bearing. 


\section{RESULTS}

In the test rig, see Fig. 8, three rectangular hydrostatic bearings are used (numbers 4, 5 and 6). The gap between the hydrostatic bearing and pressure plate is measured with sensors 1,2 and 3. The progressive flow controller is dimensioned to these existing rectangular pockets. The dimensions of the hydrostatic bearing and the test conditions of the test rig are listed in Table I.

Table I: Dimension of the hydrostatic bearing and test conditions.

\begin{tabular}{|l|c|}
\hline \multicolumn{1}{|c|}{ Parameter } & Characteristic value \\
\hline Supply pressure $p_{P}$ & \\
\hline Fluid unit & $100 \mathrm{e} 5 \mathrm{~N} / \mathrm{m}^{2}$ \\
\hline Fluid temperature $T_{\text {Fluid }}$ & $40^{\circ} \mathrm{C}$ \\
\hline Density of the fluid $\varrho$ & $848 \mathrm{~kg} / \mathrm{m}^{3}$ \\
\hline Kinematic viscosity $v$ & $46 \mathrm{~mm}^{2} / \mathrm{s}$ \\
\hline \multicolumn{1}{|c|}{ Progressive Flow Controller } & \\
\hline Length of the annular throttle $l_{K}$ & $7 \mathrm{~mm}$ \\
\hline Stroke of the control piston $x$ & $0-7 \mathrm{~mm}$ \\
\hline Diameter of the control piston $d_{F C}$ & $6 \mathrm{~mm}$ \\
\hline Area of the control piston $A_{F C}$ & $28,27 \mathrm{~mm}$ \\
\hline Spring rate $c_{S}$ & $40,252 \mathrm{~N} / \mathrm{mm}^{2}$ \\
\hline \multicolumn{1}{|c|}{ Hydrostatic Bearing } & \\
\hline Pocket pressure $p_{P o c k e t}$ & $0-100 \mathrm{e} 5 \mathrm{~N} / \mathrm{m}^{2}$ \\
\hline Number of pockets & 3 \\
\hline Max. force $F_{\text {max }}$ & $54 \mathrm{kN}$ \\
\hline Setpoint of the bearing gap $h_{\text {set }}$ & $40 \mu \mathrm{m}$ \\
\hline Average length of the pocket $b$ & $160 \mathrm{~mm}$ \\
\hline Width of the pocket $l$ & $8 \mathrm{~mm}$ \\
\hline Effective bearing area $A_{\text {eff }}$ & $1600 \mathrm{~mm}$ \\
\hline Enclosed oil volume $V_{0}$ & $4530 \mathrm{~mm}{ }^{3}$ \\
\hline
\end{tabular}

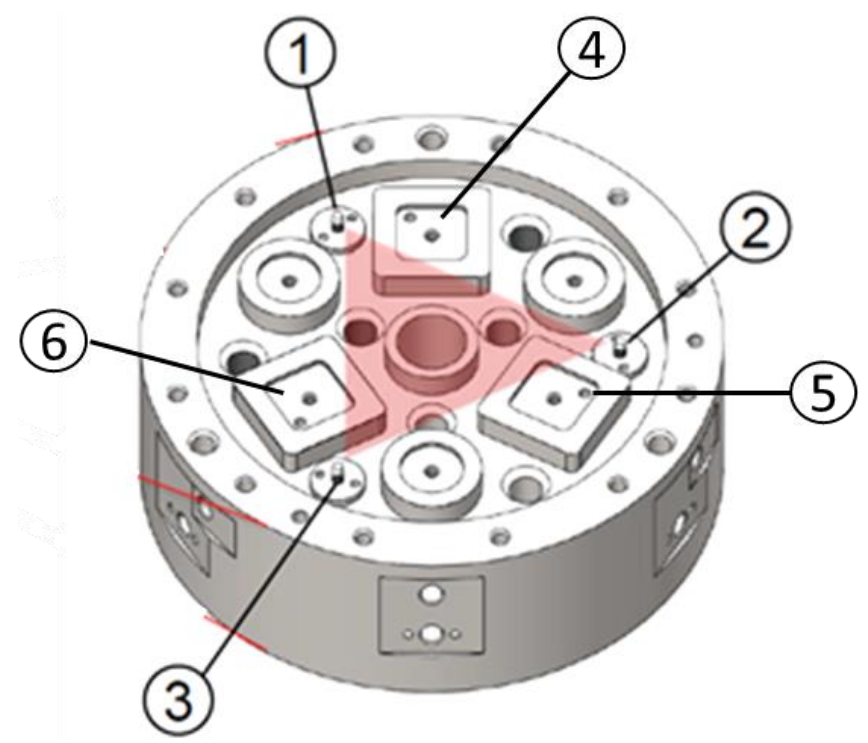

Figure 8: Sketch of the hydrostatic bearings in the test rig. 


\subsection{Calculated shape of the control edge of the progressive flow controller}

Fig. 9 shows the calculated shape of the control edge of the progressive flow controller. In the $\mathrm{x}$-direction the length of the control piston is shown, and in the y-direction the radius of the control piston. The typical trumpet shape can be seen, which results from the fact that the gap height changes the flow with the third power.

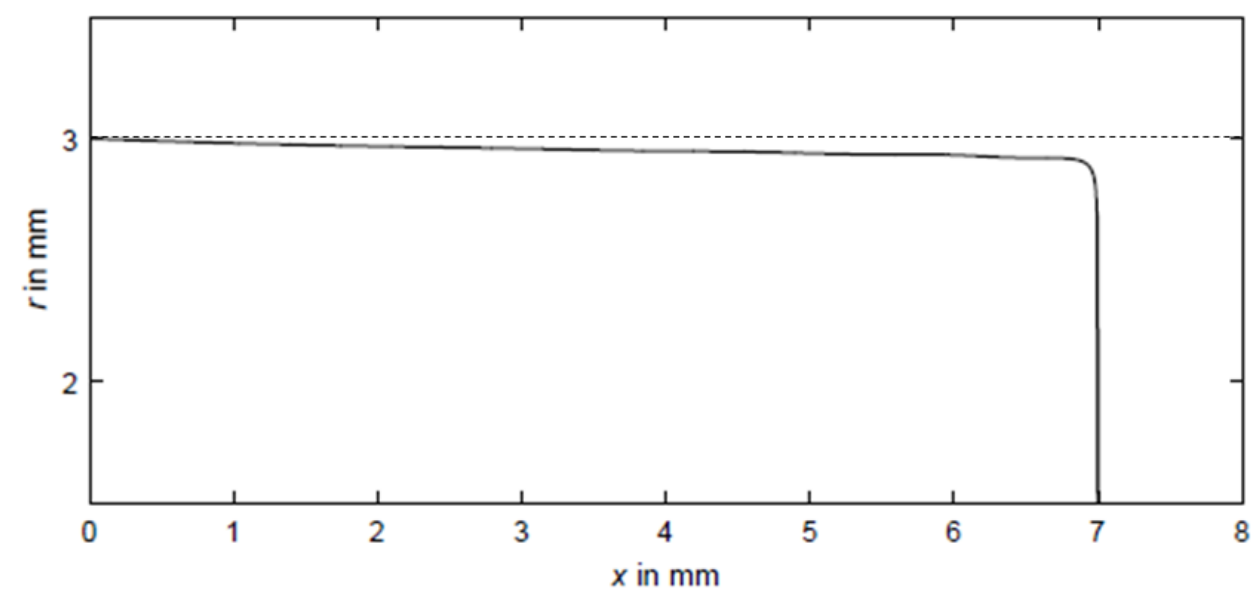

Figure 9: Calculated shape of the control edge of the progressive flow controller.

This calculation is a static calculation, and the used Differential Equation - Eq. (3) is transformed so that $h(x)$ can be calculated.

\subsection{Validation of the calculated control edge}

The validation of the calculated control edge was done with measurements on the test rig. Therefore, prototypes of the progressive flow controller were produced, and static and dynamic measurementstaken. Although the measurement of the step response is a dynamic measurement, in our case this measurement will count to the static measurements, because only the resulting gap height is of interest.

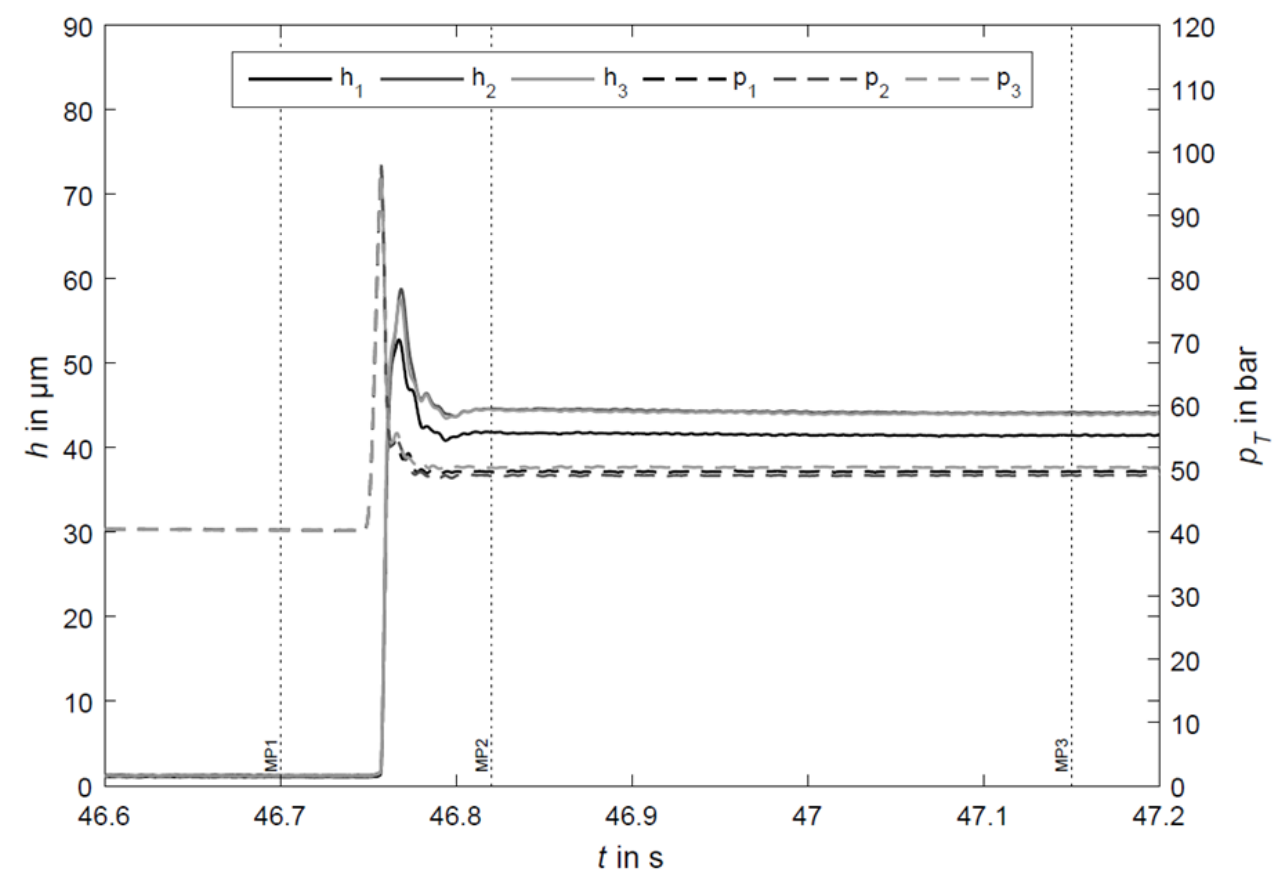

Figure 10: Measured gap height (static test). 


\section{Static Results}

In the static measurement, the hydrostatic bearing will be loaded with $50 \%$ of the maximal load of $54 \mathrm{kN}$. In Fig. 10 it can be seen that, in the simulation, the gap of the hydrostatic bearing is exactly $40 \mu \mathrm{m}$, see Fig. 11. This exact gap results from the fact that the shape of the control edge is calculated for a gap of $40 \mu \mathrm{m}$, while, on the test rig, the gap of the three hydrostatic bearings is between $41 \mu \mathrm{m}$ and $44 \mu \mathrm{m}$. The difference of only $4 \mu \mathrm{m}$ results mostly in the production tolerances of the prototypes, but also friction might play a role.

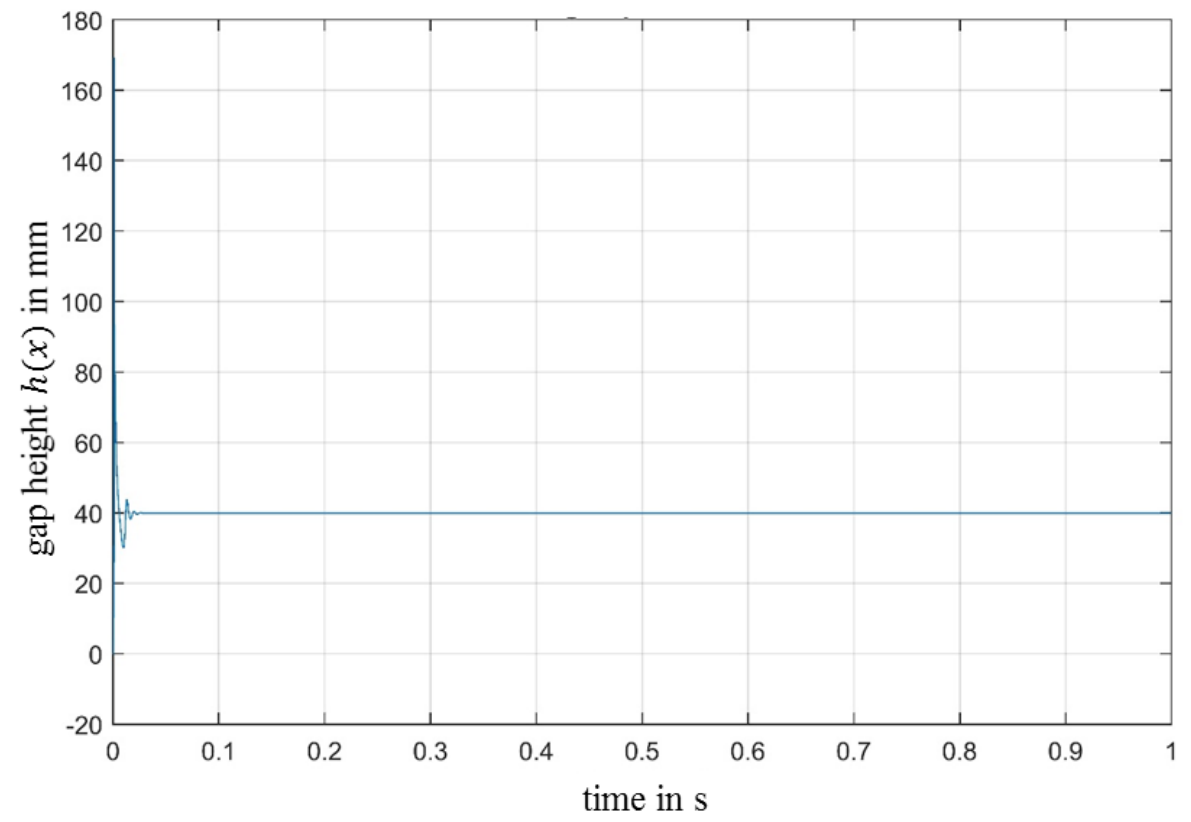

Figure 11: Calculated gap height of the hydrostatic bearing (static test).

\section{Dynamic Results}

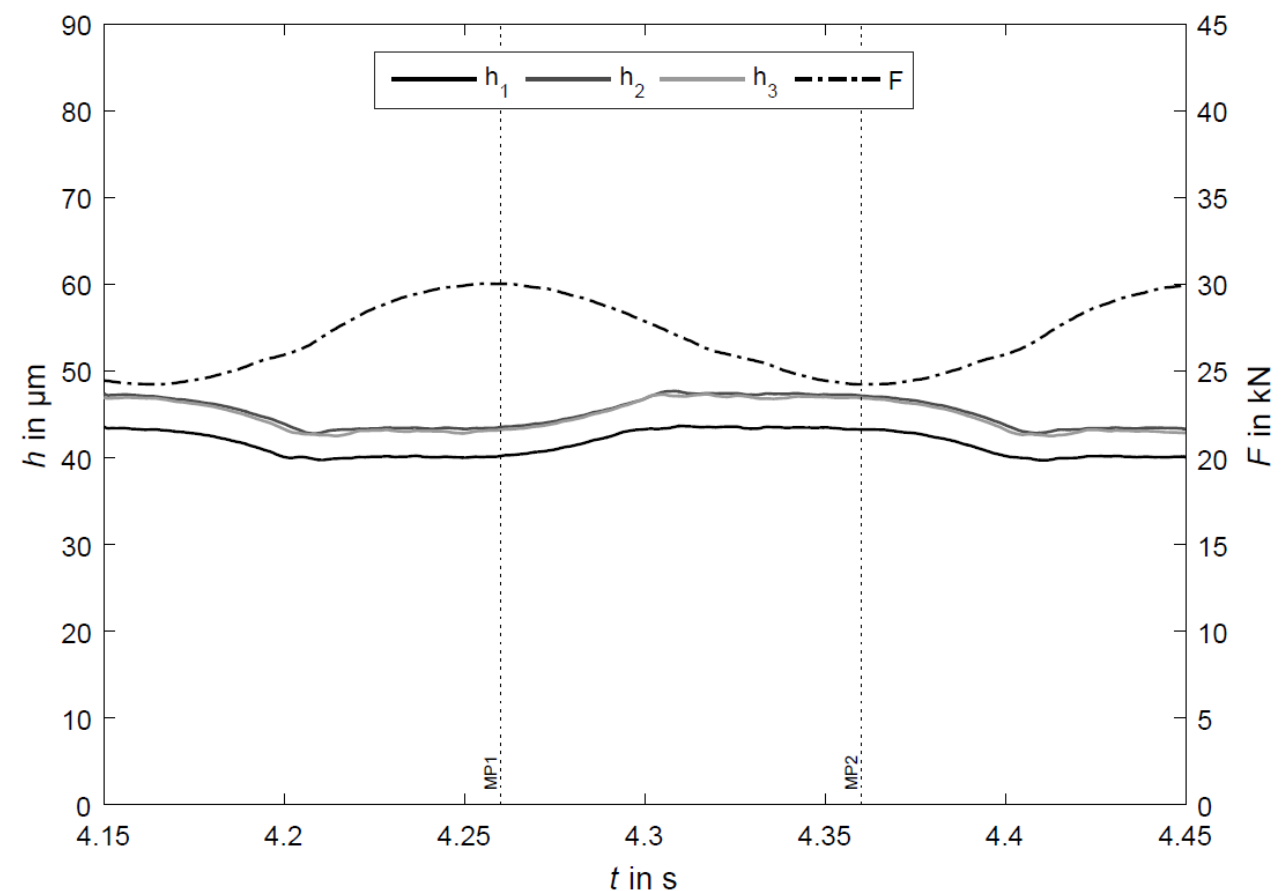

Figure 12: Measured gap height (dynamic test).

The dynamic test shown in Fig. 12 was done with a static load of $27 \mathrm{kN}$ and an overlaid sine wave load of $3 \mathrm{kN}$ with a frequency of $5 \mathrm{~Hz}$. For this case, it can be seen in Fig. 13 that the 
gap height of the hydrostatic bearing changes in the simulation between $39,5 \mu \mathrm{m}$ and $40,5 \mu \mathrm{m}$. On the test rig, the gap height changes under these test conditions between $40 \mu \mathrm{m}$ and $47 \mu \mathrm{m}$. The shape of the change of the gap height is not a clear sine wave. This results from the fact that the fluid must be squired out from the hydrostatic bearing during the load increasing, and for friction effects on the control piston of the progressive flow controller. While the friction of the control piston is considered in the mathematical model, the other effect is not considered in the 1-D simulation.

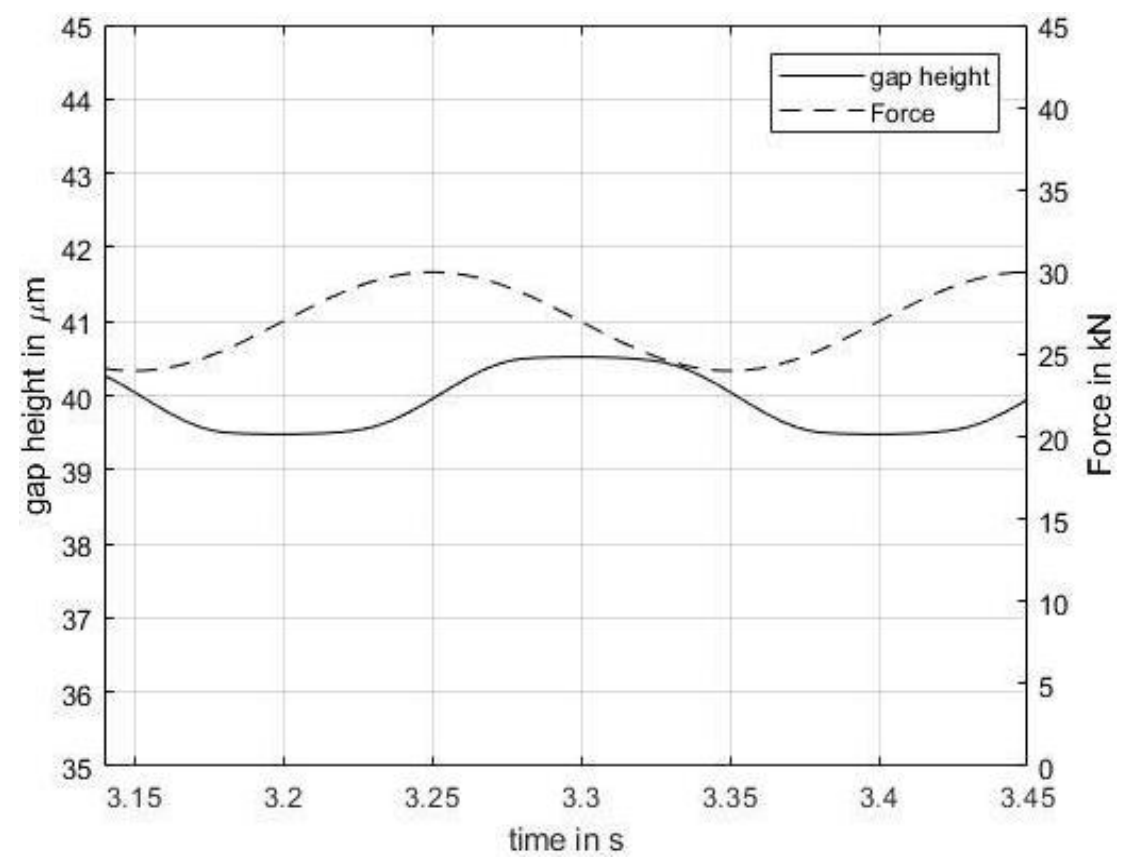

Figure 13: Calculated gap height of the hydrostatic bearing (dynamic test).

\section{CONCLUSION}

It could be shown that it is possible to calculate with a simple 1-D simulation the shape of the control edge of a progressive flow controller to get a constant gap height of a hydrostatic bearing independent of the load on the bearing. Thereby, complex 3-D simulations are not absolutely necessary for the dimensioning of the control edge of the progressive flow controller, and it is possible to design different progressive flow controllers very fast for different hydrostatic bearings.

For stationary conditions only, the production tolerances of the progressive flow controller give some differences in the gap height of the three bearings of the test rig. The correlation between the simulated gap height and the measured gap height for the dynamic load cases shows some differences. To get better results, the test rig must be implemented better into the simulation.

\section{REFERENCES}

[1] Gold, S.; Schneider, M.; Weber, J. (2013). Entwicklung und Untersuchung eines neuartigen Gleitlagers für Propellerwellen in Pod-Antrieben, Ölhydraulik+Pneumatik Journal, Vol. 4, 16-26

[2] Wang, Y.; Liu, Z.; Cai, L.; Cheng, Q.; Dong, X. (2018). Optimization of oil pads on a hydrostatic turntable for supporting energy conservation based on particle swarm optimization, Strojniski vestnik - Journal of Mechanical Engineering, Vol. 64, No. 2, 95-104, doi:10.5545/svime.2017.4742 
[3] Strmčnik, E.; Majdič, F. (2018). The pressure and efficiency characteristic of hydraulic gerotor motor with the floating outer ring, Technical Gazette, Vol. 25, No. 2, 609-615, doi:10.17559/TV20161201093324

[4] Chen, D.; Fan, J.; Zhang, F. (2012). Dynamic and static characteristics of hydrostatic spindle for machine tools, Journal of Manufacturing Systems, Vol. 31, No. 1, 26-33, doi:10.1016/ j.jmsy.2010.11.006

[5] Edler, J.; Steffan, M. (2017). Verification of a simulation to predict the transmission behaviour of hydrostatic bearing on machine tools, Proceedings of the International Conference Fluid Power 2017, 175-184

[6] Liang, P.; Lu, C.; Pan, W.; Li, S. (2014). A new method for calculating the static performance of hydrostatic journal bearing, Tribology International, Vol. 77, 72-77, doi:10.1016/ j.triboint.2014.04.019

[7] Steffan, M.; Haas, F.; Zopf, P.; Edler, J. (2017). Optimierung der Schleifbearbeitung mittels OPC UA: Neue Prozessregelung zur Vermeidung von thermischer Randzonenschädigung, Zeitschrift für wirtschaftlichen Fabrikbetrieb, Vol. 112, No. 3, 137-141, doi:10.3139/104.111687

[8] Herakovič, N.; Duhovnik, J.; Šimic, M. (2015). CFD simulation of flow force reduction in hydraulic valves, Technical Gazette, Vol. 22, No. 2, 453-463, doi:10.17559/TV-20141128090939

[9] Brnčić, D.; Gregov, G. (2017). Numerical simulation study of parallel hydraulic hybrid system for a delivery van, Technical Journal, Vol. 11, No. 1-2, 21-28

[10] Kim, C.-J.; Oh, J.-S.; Park, C.-H. (2014). Modelling vibration transmission in the mechanical and control system of a precision machine, CIRP Annals, Vol. 63, No. 1, 349-352, doi:10.1016/ j.cirp.2014.03.133

[11] Horvart, F. E.; Braun, M. J. (2011). Comparative experimental and numerical analysis of flow and pressure fields inside deep and shallow pockets of a hydrostatic bearing, Tribology Transactions, Vol. 54, No. 4, 548-567, doi:10.1080/10402004.2011.575535

[12] Schönfeld, R. (1999). A controller for controlling at least one hydrostatic or aerostatic pocket of a bearing, threaded spindle nut or a guide supplied media flow, Patent DE19737781A1

[13] Mörwald, G.; Edler, J.; Hochleitner, H. (2013). Test bed for hydrostatic bearing gap, Proceedings of the International Conference Fluid Power 2013, 179-185 